\title{
Initial Experience with Nab-Paclitaxel for Patients with Advanced Gastric Cancer: Safety and Efficacy
}

\author{
YOSHIKAZU KANAZAWA, ITSUO FUJITA, DIASUKE KAKINUMA, HIROKI ARAI, \\ KUNIHIKO MATSUNO, TOMOHIRO SHIMODA, KAZUHIDE KO, SHUNJI KATO and EIJI UCHIDA
}

Department of Gastrointestinal and Hepatobiliary-Pancreatic surgery, Nippon Medical School, Tokyo, Japan

\begin{abstract}
Background: Taxane-based chemotherapy is useful for peritoneal dissemination control in advanced/recurrent gastric cancer; however, insufficient relative dose intensity (RDI) may preclude disease control achievement. Nab-paclitaxel, with high tumour permeability, is a promising second- or later-line treatment. Patients and Methods: We retrospectively evaluated the clinical safety and efficacy of nab-paclitaxel for advanced/recurrent gastric cancer patients treated between April 2013 and December 2015. The response rate, RDI and survival outcomes were assessed. Results: Of 14 evaluated patients, 4 achieved partial response. Overall response and the disease control rates were $28.5 \%$ and $64.2 \%$, respectively. Nine patients developed peritoneal metastasis; their overall response and disease control rate were $22.2 \%$ and $66.6 \%$. Patients with high RDI $(\geq 80 \%)$ showed longer progression-free and overall survival than those with low RDI $(\leq 80 \%)$ (11.8 vs. 4.0 months, $p=0.02$; and 14.3 vs. 8.2 months, $p=0.03$, respectively). Conclusion: Nab-paclitaxel, at an $R D I \geq 80 \%$, was safe and beneficial for these patients.
\end{abstract}

Although the prognosis of unresectable/recurrent gastric cancer is poor, chemotherapy with S-1 (tegafur plus gimeracil plus oteracil potassium) remarkably improves treatment outcomes $(1,2)$. In Japan, $S-1$ is also used for adjuvant therapy and recommended as first-line treatment of unresectable/recurrent gastric cancer $(2,3)$. Taxanes are mainly used for second- or later-line chemotherapy (4). Further, taxane-based chemotherapy has been shown to

Correspondence to: Yoshikazu Kanazawa, Department of Gastrointestinal and Hepatobiliary-Pancreatic surgery, Nippon Medical School, 1-1-5, Sendagi, Bunkyo-ku, Tokyo 113-8603, Japan. Tel: +81 338222131, Fax: +81 356850989, e-mail: kanazawa-y@nms.ac.jp

Key Words: Advanced gastric cancer, nab-paclitaxel, relative dose intensity, peritoneal dissemination. prolong patients' expected survival time (4-8). Many patients planned to undergo second-line chemotherapy have a poor Eastern Cooperative Oncology Group (ECOG) performance status (PS). Nevertheless, continued treatment and sustained relative dose intensity (RDI) may improve patient's prognosis $(9,10)$.

Nanoparticle albumin-bound (nab)-paclitaxel is paclitaxel linked to $130-\mathrm{nm}$ albumin nanoparticles. It is a new class of anticancer agent that incorporates albumin particle technology. Nab-paclitaxel allows for a safe infusion of significantly higher doses of paclitaxel than with standard paclitaxel therapy. Additionally, nab-paclitaxel allows shorter infusion schedules without the need for premedication for hypersensitivity reactions as with standard paclitaxel. Furthermore, nab-paclitaxel shows an increased paclitaxel transport across endothelial cells and greater antitumor activity compared with standard paclitaxel in a preclinical study (11).

In a domestic phase II clinical trial, patients with treatment-refractory cancer who were treated with first-line chemotherapy containing S-1 showed a favourable response rate of $28 \%$, progression-free survival (PFS) of 2.9 months and overall survival (OS) of 9.2 months after treatment with nab-paclitaxel (12). However, this phase II clinical trial is the only one to evaluate nab-paclitaxel treatment for patients with gastric cancer. Thus, the safety and survival benefits of nab-paclitaxel in clinical practice remain unclear. In this retrospective study, we evaluated the clinical safety and efficacy of nab-paclitaxel for unresectable/recurrent gastric cancer patients.

\section{Patients and Methods}

Patient selection. We included unresectable/recurrent gastric cancer patients treated at out Institute between April 2013 and December 2015. The inclusion criteria were as follows; (i) patients with unresectable/recurrent gastric cancer, (ii) aged between 20 and 85 years, (iii) with ECOG PS 0-2, (iv) with or without history of gastrectomy, and (v) adequate hematologic, liver and renal functions (i.e., neutrophils $>1,500 / \mathrm{ml}$; platelet count $>100,000 / \mathrm{ml}$; estimated glomerular filtration rate $\left(\right.$ eGFR) $>40 \mathrm{ml} / \mathrm{min} / 1.73 \mathrm{~m}^{3}$; total 
Table I. Basic characteristics of the 14 patients.

\begin{tabular}{|c|c|c|c|c|c|c|c|c|c|c|c|c|}
\hline Case & Age & Gender & PS & $\begin{array}{l}\text { Line } \\
\text { setting }\end{array}$ & $\begin{array}{l}\text { Histological } \\
\text { type }\end{array}$ & \multicolumn{2}{|c|}{$\begin{array}{l}\text { Metastatic } \\
\text { site }\end{array}$} & $\begin{array}{l}\text { Total } \\
\text { course }\end{array}$ & $\begin{array}{c}\text { Dose }(\mathrm{mg}) \times \\
\text { course }\end{array}$ & $\begin{array}{l}\text { Total dosage } \\
\quad(\mathrm{mg})\end{array}$ & $\begin{array}{l}\text { RDI } \\
(\%)\end{array}$ & $\begin{array}{c}\text { Best } \\
\text { response }\end{array}$ \\
\hline 1 & 63 & Male & 2 & 2 & Undifferentiated & $\mathrm{P}$ & & 4 & $360 \times 4$ & 1,440 & 76.9 & PD \\
\hline 2 & 65 & Female & 2 & 2 & Differentiated & $\mathrm{P}$ & & 9 & $260 \times 6$ & 2,250 & $\begin{array}{c}74 \\
878\end{array}$ & SD \\
\hline 3 & 73 & Female & 1 & 2 & Undifferentiated & $\mathrm{P}$ & & 12 & $\begin{array}{c}230 \times 3 \\
280 \times 6 \\
300 \times 2 \\
320 \times 4\end{array}$ & 3,560 & 87.8 & PR \\
\hline 4 & 68 & Male & 1 & 3 & Differentiated & $\mathrm{Lu}$ & & 7 & $\begin{array}{c}360 \times 2 \\
288 \times 3 \\
300 \times 2\end{array}$ & 1,896 & 74.4 & SD \\
\hline 5 & 63 & Male & 0 & 2 & Differentiated & $\mathrm{P}$ & PAN & 7 & $350 \times 7$ & 2,450 & 81.6 & PR \\
\hline 6 & 74 & Female & 1 & 2 & Undifferentiated & $\mathrm{P}$ & & 14 & $\begin{array}{l}300 \times 1 \\
320 \times 13\end{array}$ & 4,460 & 96.5 & PR \\
\hline 7 & 78 & Male & 1 & 2 & Differentiated & $\mathrm{P}$ & & 8 & $380 \times 8$ & 3,040 & 91.3 & $\begin{array}{c}\text { Non-PR/ } \\
\text { non-PD }\end{array}$ \\
\hline 8 & 74 & Male & 1 & 3 & Differentiated & $\mathrm{Li}$ & & 2 & $\begin{array}{l}320 \times 1 \\
250 \times 1\end{array}$ & 570 & 68.5 & $\mathrm{PD}$ \\
\hline 9 & 73 & Male & 2 & 2 & Differentiated & $\mathrm{P}$ & & 6 & $330 \times 6$ & 1,980 & 84.6 & PD \\
\hline 10 & 67 & Male & 1 & 3 & Undifferentiated & $\mathrm{P}$ & & 6 & $\begin{array}{c}350 \times 2 \\
390 \times 2 \\
360 \times 2\end{array}$ & 2,200 & 94 & SD \\
\hline 11 & 66 & Female & 0 & 3 & Differentiated & $\mathrm{P}$ & $\mathrm{Li}$ & 4 & $300 \times 4$ & 1,200 & 76.9 & SD \\
\hline 12 & 68 & Male & 1 & 2 & Undifferentiated & $\mathrm{Li}$ & PAN & 8 & $290 \times 8$ & 2,320 & 74.4 & PR \\
\hline 13 & 68 & Male & 1 & 2 & Undifferentiated & $\mathrm{Li}$ & PAN & 15 & $\begin{array}{l}320 \times 7 \\
250 \times 8\end{array}$ & 4,240 & 72.4 & SD \\
\hline 14 & 73 & Male & 1 & 2 & Differentiated & $\mathrm{P}$ & & 8 & $\begin{array}{c}290 \times 1 \\
330 \times 7\end{array}$ & 1,640 & 84.6 & $\begin{array}{c}\text { Non-PR/ } \\
\text { non-PD }\end{array}$ \\
\hline
\end{tabular}

P, Peritoneum; Lu, lung; Li, liver; PAN, para-aortic lymph nodes; PD, progressive disease; SD, stable disease; PR, partial response; RDI, relative dose intensity; PS, performance status.

bilirubin concentration $\leq$ two times the upper limit of normal; and liver transaminase or alkaline phosphatase concentrations $\leq$ three times the upper limit of normal). Exclusion criteria were as follows: (a) patients with active malignant disease, (b) with severe comorbidity, (c) pregnant women.

Treatment. Nab-paclitaxel was administered intravenously over 30 minutes at a dose of $260 \mathrm{mg} / \mathrm{m}^{2}$ on day 1 of 3 -week cycles. In consideration of the PS, a one- or two-level dose reduction was employed during the initial treatment.

End-points and evaluation of clinical response. The primary endpoint was safety in clinical practice. The secondary end-points were response rate, OS and PFS. Tumour response was assessed with computed tomography according to the Response Evaluation Criteria in Solid Tumors version 1.1 (RECIST) (13). We calculated the RDI and adverse events were assessed using Common Terminology Criteria for Adverse Events ver 4.0.g

OS was defined as the time elapsed from the first visit to death. PFS was defined as the time elapsed from the day of nab-paclitaxel treatment start to the date of the first occurrence of disease progression or death by any cause. The follow-up period was closed on December 2016. Survival curves were constructed using the Kaplan-Meier method.

\section{Results}

Patients' characteristics. Fourteen patients were included in this study. Patients' characteristics are shown in Table I. Patients had a median age of 69 (range $=63-78)$ years. Three patients had PS of 2; nine patients, 1; and two patients, 0. The histological type was differentiated in eight patients $(57 \%)$ and undifferentiated in six. The metastatic site was the peritoneum in nine patients; liver, four; and lungs, one patient (including overlap). Peritoneal metastasis was the most common. S-1, cisplatin and CPT-11 were mainly used for first- or second-line chemotherapy before nab-paclitaxel treatment.

The initial dose of nab-paclitaxel was as follows: $260 \mathrm{mg} / \mathrm{m}^{2}$ for five patients; $220 \mathrm{mg} / \mathrm{m}^{2}$ for four patients; and $180 \mathrm{mg} / \mathrm{m}^{2}$ for five patients. The dose was decreased in nine patients $(64.3 \%)$ and increased in three. The number of treatment courses, RDI and reasons for treatment discontinuation are shown in Table II. The median total number of treatment courses was 8 (2-16). The median RDI was $79.3 \%$ based on the dose given during each course for each patient and the 
Table II. Treatment status and reasons for discontinuation $(n=14)$.

\begin{tabular}{lc}
\hline Dosage & Median \\
\hline $\begin{array}{l}\text { Dosage course number } \\
\text { Relative does intensity (\%), } \\
\text { (Prescription dose/Planning dose) }\end{array}$ & $8(2-16)$ \\
\hline Situation & $79.30 \%$ \\
\hline Ongoing & No. of case \\
treatment discontinuation reason & 2 \\
$\quad$ Progressive disease & \\
Adverse event & 8 \\
Principal hope & 2 \\
Treatment-related death & 2 \\
\hline
\end{tabular}

Table III. Adverse events.

\begin{tabular}{lcc}
\hline \multirow{2}{*}{ Adverse Event } & \multicolumn{2}{c}{ All patients $(\mathrm{n}=14)$} \\
\cline { 2 - 3 } & $\begin{array}{c}\text { All Grade } \\
\mathrm{n}(\%)\end{array}$ & $\begin{array}{c}\text { Grade 3-4 } \\
\mathrm{n}(\%)\end{array}$ \\
\hline Neutropenia & $4(28.5 \%)$ & $1(7.1 \%)$ \\
Anorexia & $8(57.1 \%)$ & - \\
Nausea & $1(7.1 \%)$ & - \\
Diarrhea & $1(7.1 \%)$ & - \\
Alopecia & $4(28.5 \%)$ & - \\
Peripheral sensory neuropathy & $10(71.4 \%)$ & $1(7.1 \%)$ \\
Pyrexia & $1(7.1 \%)$ & - \\
\hline
\end{tabular}

specified dose of nab-paclitaxel $\left(260 \mathrm{mg} / \mathrm{m}^{2}\right)$. The reasons for treatment discontinuation were disease progression $(57 \%$, $8 / 14)$, adverse events $(14 \%, 2 / 14)$ and patient preference $(14 \%$, $2 / 14)$. The treatment is ongoing in two patients.

Adverse events. The main adverse events of any grade were peripheral neuropathy $(71.4 \%, \mathrm{n}=10)$, anorexia $(57 \%)$, neutropenia $(29 \%)$ and alopecia $(29 \%)$. Nine patients presented Grade 1 or Grade 2 peripheral neuropathy. Two patients discontinued because of adverse events: one patient with Grade 3 peripheral neuropathy and one patient with Grade 3 rash. No treatment-related death occurred (Table III).

Efficacy. Table IV shows the response to treatment of the 14 patients. Of all patients, 4 achieved partial response. The overall response rate was $28.5 \%$ and the disease control rate $64.2 \%$. In a subset of nine patients with peritoneal metastasis, the overall response rate was $22.2 \%$ and the disease control rate $66.6 \%$.
Table IV. Clinical responses of patients.

\begin{tabular}{lcc}
\hline & $\begin{array}{c}\text { No. of patients } \\
(\mathrm{n}=14)\end{array}$ & $\begin{array}{c}\text { Peritoneal metastasis } \\
(\mathrm{n}=9)\end{array}$ \\
\hline Complete response & 0 & 0 \\
Partial response & 4 & 2 \\
Stable disease & 5 & 4 \\
Progressive disease & 3 & 1 \\
Not evaluable & 2 & 2 \\
Overall response rate $(\%)$ & $28.5 \%$ & $22.2 \%$ \\
Disease control rate $(\%)$ & $64.2 \%$ & $66.6 \%$ \\
\hline
\end{tabular}

Table V. Summary of results of trials using nab-paclitaxel or paclitaxel in patients with gastric cancer.

\begin{tabular}{lccc}
\hline Variable & Present study & Phase II trial & WJOG4007 trial \\
\cline { 2 - 4 } Regimen & $\begin{array}{c}\text { Nab-Paclitaxel } \\
\text { Tri-weekly }\end{array}$ & $\begin{array}{c}\text { Nab-Paclitaxel } \\
\text { Tri-weekly }\end{array}$ & $\begin{array}{c}\text { Paclitaxel } \\
\text { Weekly }\end{array}$ \\
\hline Age median (range) & $69(63-78)$ & $63.5(34-74)$ & $64.5(37-75)$ \\
Patients (n) & 14 & 54 & 91 \\
Overall PR (\%) & $28.50 \%$ & $27.80 \%$ & $20.90 \%$ \\
DCR (\%) & $64.20 \%$ & $59.30 \%$ & $62.60 \%$ \\
Median OS & 10.45 & 9.2 & 9.5 \\
Median PFS & 5.95 & 2.9 & 3.6 \\
\hline
\end{tabular}

RR, Response rate; DCR, disease control rate; OS, overall survival; PFS, progression-free survival.

Figure 1 shows the Kaplan-Meier survival curves. Median OS was 10.5 (95\% confidence interval $(\mathrm{CI})=3.8-14.3)$ months and the median PFS 6.0 (95\% CI=3.5-11.8) months. Based on the median RDI of $79.3 \%, 80 \%$ was set as the RDI cut-off and patients were divided into a $\geq 80 \%$ RDI group (high RDI) and $\leq 80 \%$ RDI group (low RDI). The PFS of patients in the high RDI group was better than that of patients in the low RDI group (11.8vs. 4.0 months, $p=0.02$, Figure 2A). The OS of patients in the high RDI group was also better than that of the patients in the low RDI group (14.3 vs. 8.2 months, $p=0.03$, Figure 2).

\section{Discussion}

This study has demonstrated three important findings. First, nab-paclitaxel is safe for second- or later-line chemotherapy for advanced/recurrent gastric cancer patients in clinical practice. Second, the clinical outcomes achieved with nabpaclitaxel as a second- or later-line chemotherapy agent are 

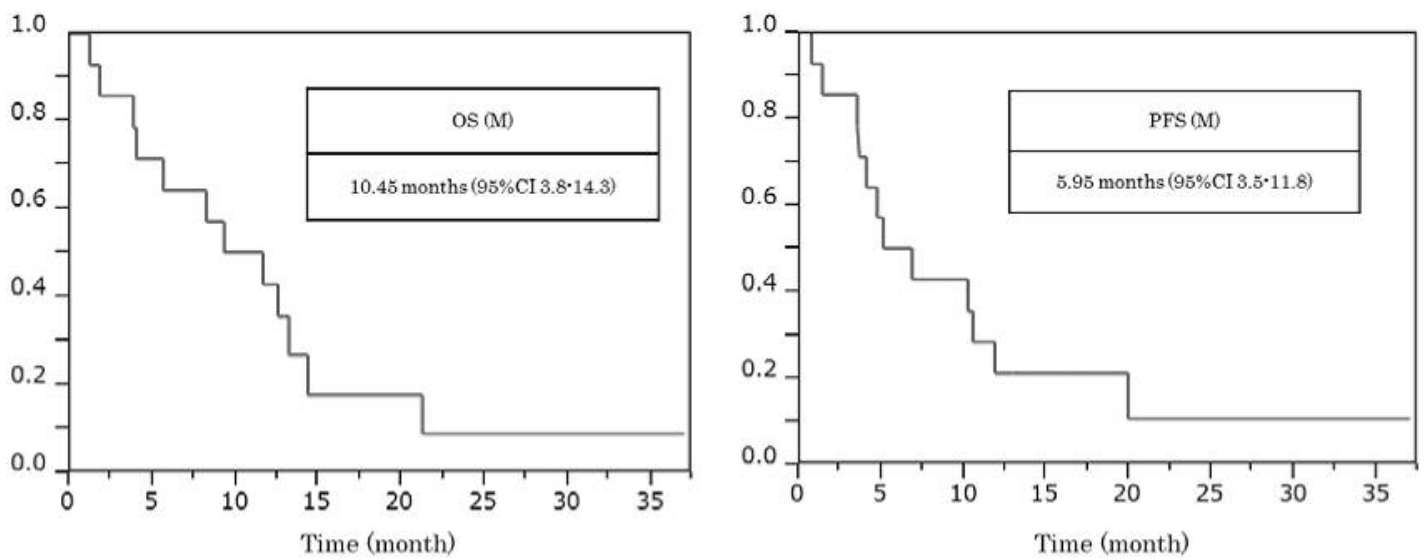

Figure 1. Kaplan-Meier curves of overall and progression-free survival of the 14 patients. OS, Overall survival; PFS, progression-free survival; M, months; CI, confidence interval.
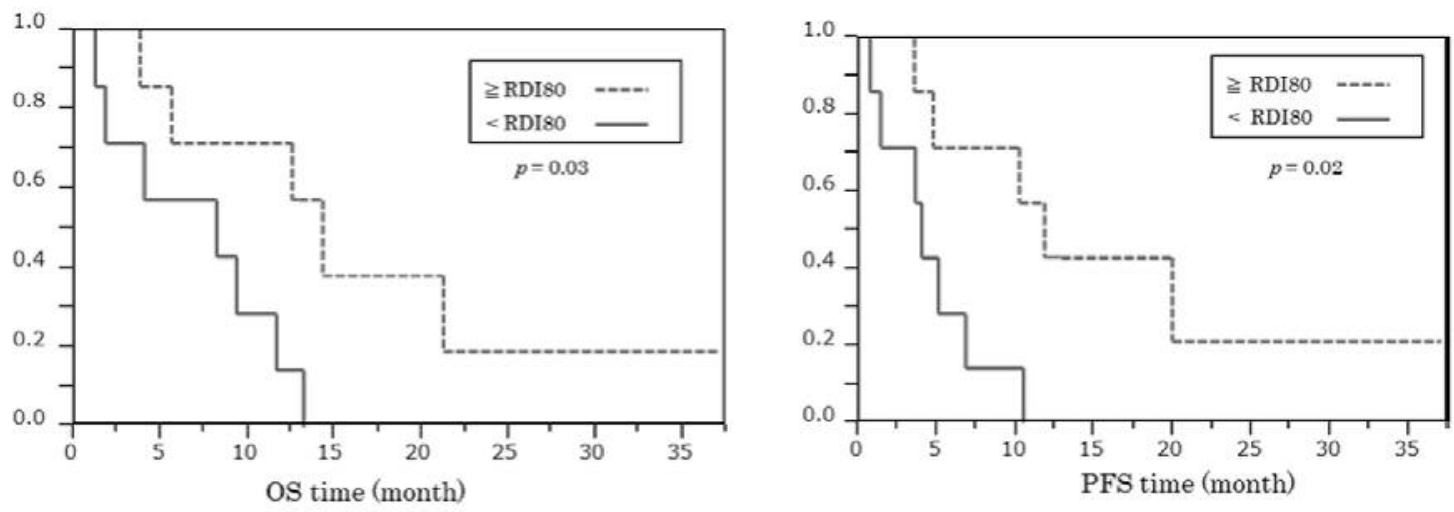

Figure 2. Overall survival (OS) and progression-free survival (PFS) with a relative dose intensity (RDI) cut-off of $80 \%$.

acceptable. Third, a sufficient RDI is needed for patients treated with nab-paclitaxel to benefit from such clinical outcomes.

Nab-paclitaxel has been found to be a safe second- or later-line treatment for advanced gastric cancer, although patients undergoing second-line chemotherapy are generally in poor condition and, thus, at higher risk of developing severe adverse events. In this study, in which $29 \%$ of patients were undergoing third-line treatment, only two patients $(14 \%)$ discontinued treatment for adverse effects.

When comparing the present results with those from the WJOG 4007 trial with weekly paclitaxel (4) and the domestic phase II trial of nab-paclitaxel (12), the response rates, PFS, as well as OS, were comparable among studies and nab-paclitaxel was found to be useful for second-line chemotherapy in clinical practice (Table V). However, further prospective studies are needed to validate the benefits of second-line nab-paclitaxel for advanced gastric cancer. In the WJOG 4007 trial, which included 91 patients treated with weekly paclitaxel, the response rate was $20.9 \%$; the disease control rate, 64.2\%; PFS, 3.6 months; and OS, 9.5 months (4). In the domestic phase II trial, which included 54 patients treated with tri-weekly nab-paclitaxel, the response rate was $27.8 \%$; disease control rate, $59.3 \%$; PFS, 2.9 months; and OS, 9.2 months (12). Notably, although our study included patients undergoing third-line treatment, we showed that these patients achieved acceptable and comparable response rates $(28.5 \%)$, disease control rate (64.23\%), PFS (6.0 months) and OS (10.5 months).

In order for patients to obtain the clinical benefits from nab-paclitaxel treatment, the RDI must be sufficiently high and maintained throughout the treatment. Although dose reductions are inevitable in second- or later-lines of chemotherapy, such dose reductions may also lead to 
decreased antitumor effects. For other malignancies, including breast and haematological cancers, a higher RDI has been demonstrated to contribute to survival $(9,10)$. In the present study, the median RDI was $79.3 \%$; thus, an RDI of $80 \%$ was considered as the cut-off value. Patients with an RDI of $\geq 80 \%$ had significantly better PFS and OS. Further, this indicates that dose reductions of $\geq 20 \%$ should be considered carefully and that providing supportive care to maintain the patient's physical condition may be important.

Recently, improvements in survival outcomes have been observed in patients with advanced gastric cancer who received combination treatment with ramucirumab and paclitaxel in the RAINBOW and REGARD trials; however, treatment complications, including oncologic emergencies, such as perforation, were reported. Therefore, such combination treatments should be administered with care $(14,15)$. Conversely, in the ABSOLUTE trial, weekly nabpaclitaxel therapy was demonstrated to be non-inferior to 3weekly nab-paclitaxel with a high response rate and a favourable rate of ascites decrease (16). These results indicate that further survival benefits can be expected from weekly nab-paclitaxel therapy in the future, as well as with the addition of ramucirumab to the second-line therapy with nab-paclitaxel for advanced gastric cancer.

This retrospective study has several limitations. First, it included only a small number of patients. Second, this study included patients undergoing not only second-line but also third-line treatment. Third, the criteria for dose reduction are not standardized. To evaluate the safety and benefits of nabpaclitaxel as second-line chemotherapy in clinical practice, large prospective studies, including only patients planned to undergo second-line treatment, are needed.

Nab-paclitaxel, as second- or later-line chemotherapy agent, is safe and beneficial for patients with unresectable/ recurrent gastric cancer. Maintaining the RDI $\geq 80 \%$ is important to achieve the clinical benefits of nab-paclitaxel.

\section{Conflicts of Interest}

None declared.

\section{Acknowledgements}

This works supported in part by the Medical staff of Nippon Medical School Hospital (data management).

\section{References}

1 Boku N, Yamamoto S, Fukuda H, Shirao K, Doi T, Sawaki A, Koizumi W, Saito H, Yamaguchi K, Takiuchi H, Nasu J and Ohtsu A: Gastrointestinal Oncology Study Group of the Japan Clinical Oncology Group. Fluorouracil versus combination of irinotecan plus cisplatin versus $\mathrm{S}-1$ in metastatic gastric cancer: a randomised phase 3 study. Lancet Oncol 10(11): 1063-1069, 2009.
2 Koizumi W, Narahara H, Hara T, Takagane A, Akiya T, Takagi M, Miyashita K, Nishizaki T, Kobayashi O, Takiyama W, Toh Y, Nagaie T, Takagi S, Yamamura Y, Yanaoka K, Orita H and Takeuchi M: S-1 plus cisplatin versus S-1 alone for first-line treatment of advanced gastric cancer (SPIRITS trial): A phase III trial. Lancet Oncol 9(3): 215-221, 2008.

3 Sasako M, Sakuramoto S, Katai H, Kinoshita T, Furukawa H, Yamaguchi T, Nashimoto A, Fujii M, Nakajima T and Ohashi Y: Five-year outcomes of a randomized phase III trial comparing adjuvant chemotherapy with S-1 versus surgery alone in stage II or III gastric cancer. J Clin Oncol 29(33): 4387-4393, 2011.

4 Hironaka S, Ueda S, Yasui H, Nishina T, Tsuda M, Tsumura T, Sugimoto N, Shimodaira H, Tokunaga S, Moriwaki T, Esaki T, Nagase M, Fujitani K, Yamaguchi K, Ura T, Hamamoto Y, Morita S, Okamoto I, Boku N and Hyodo I: Randomized, openlabel, phase III study comparing irinotecan with paclitaxel in patients with advanced gastric cancer without severe peritoneal metastasis after failure of prior combination chemotherapy using fluoropyrimidine plus platinum: WJOG 4007 trial. J Clin Oncol 31(35): 4438-4444, 2013.

5 Kobayashi M1, Sakamoto J, Namikawa T, Okamoto K, Okabayashi T, Ichikawa $\mathrm{K}$ and Araki K: Pharmacokinetic study of paclitaxel in malignant ascites from advanced gastric cancer patients. World J Gastroenterol 12(9): 1412-1415, 2006.

6 Ajani JA, Fairweather J, Dumas P, Patt YZ, Pazdur R and Mansfield PF: Phase II study of Taxol in patients with advanced gastric carcinoma. Cancer J Sci Am 4(4): 269-274, 1988.

7 Ishigami H, Kitayama J, Kaisaki S, Hidemura A, Kato M, Otani K, Kamei T, Soma D, Miyato H, Yamashita $\mathrm{H}$ and Nagawa $\mathrm{H}$ : Phase II study of weekly intravenous and intraperitoneal paclitaxel combined with S-1 for advanced gastric cancer with peritoneal metastasis. Ann Oncol 21(1): 67-70, 2010.

8 Ishigami $\mathrm{H}$, Yamaguchi $\mathrm{H}$, Yamashita $\mathrm{H}$, Asakage $\mathrm{M}$ and Kitayama J: Surgery after intraperitoneal and systemic chemotherapy for gastric cancer with peritoneal metastasis or positive peritoneal cytology findings. Gastric Cancer 20(Suppl 1): 128-134, 2017.

9 Bonadonna G, Valagussa $\mathrm{P}$, Moliterni A, Zambetti $\mathrm{M}$ and Brambilla C: Adjuvant cyclophosphamide, methotrexate, and fluorouracil in node-positive breast cancer: The results of 20 years of follow-up. N Engl J Med 332(14): 901-906, 1995.

10 Epelbaum R, Faraggi D, Ben-Arie Y, Ben-Shahar M, Haim N, Ron Y, Robinson E and Cohen Y: Survival of diffuse large cell lymphoma. A multivariate analysis including dose intensity variables. Cancer 66(6): 1124-1129, 1990.

11 Desai N, Trieu V, Yao Z, Louie L, Ci S, Yang A, Tao C, De T, Beals B, Dykes D, Noker P, Yao R, Labao E, Hawkins M and Soon-Shiong P: Increased antitumor activity, intratumor paclitaxel concentrations, and endothelial cell transport of cremophor-free, albumin-bound paclitaxel, ABI-007, compared with cremophor-based paclitaxel. Clin Cancer Res 12(4): 13171324, 2006.

12 Sasaki Y, Nishina T, Yasui H, Goto M, Muro K, Tsuji A, Koizumi W, Toh Y, Hara T and Miyata Y: Phase II trial of nanoparticle albumin-bound paclitaxel as second-line chemotherapy for unresectable or recurrent gastric cancer. Cancer Sci 105(7): 812-817, 2014. 
13 Eisenhauer EA, Therasse P, Bogaerts J, Schwartz LH, Sargent D, Ford R, Dancey J, Arbuck S, Gwyther S, Mooney M, Rubinstein L, Shankar L, Dodd L, Kaplan R, Lacombe D and Verweij J: New response evaluation criteria in solid tumours: Revised RECIST guideline (version 1.1). Eur J Cancer 45(2): 228-247, 2009.

14 Wilke H, Muro K, Van Cutsem E, Oh SC, Bodoky G, Shimada Y, Hironaka S, Sugimoto N, Lipatov O, Kim TY, Cunningham D, Rougier P, Komatsu Y, Ajani J, Emig M, Carlesi R, Ferry D, Chandrawansa K, Schwartz JD and Ohtsu A: RAINBOW Study Group. Ramucirumab plus paclitaxel versus placebo plus paclitaxel in patients with previously treated advanced gastric or gastro-oesophageal junction adenocarcinoma (RAINBOW): A double-blind, randomised phase 3 trial. Lancet Oncol 15(11): 1224-1235, 2014.
15 Fuchs CS, Tomasek J, Yong CJ, Dumitru F, Passalacqua R, Goswami C, Safran H, dos Santos LV, Aprile G, Ferry DR, Melichar B, Tehfe M, Topuzov E, Zalcberg JR, Chau I, Campbell W, Sivanandan C, Pikiel J, Koshiji M, Hsu Y, Liepa AM, Gao L, Schwartz JD and Tabernero J: REGARD Trial Investigators. Lancet 383(9911): 31-39, 2014.

16 Koizumi W, Morita S and Sakata Y: A randomized Phase III trial of weekly or 3-weekly doses of nab-paclitaxel versus weekly doses of cremophor-based paclitaxel in patients with previously treated advanced gastric cancer (ABSOLUTE Trial). Jpn J Clin Oncol 45(3): 303-306, 2015.

Received March 6, 2017

Revised March 19, 2017

Accepted March 20, 2017 